estudos RBep

\title{
Contribuições do perspectivismo ameríndio para as pesquisas em Filosofia da Educação
}

Alexandre Simão Freitas ${ }^{\mathrm{I}, \mathrm{II}}$

http://dx.doi.org/10.24109/2176-6681.rbep.99i252.3731

\section{Resumo}

Este ensaio especulativo analisa o papel que sistemas de pensamento não ocidentais podem ocupar nas pesquisas filosófico-educacionais. A intenção é interrogar a maneira como o campo da Filosofia da Educação, no Brasil, tem reconhecido a pluralidade dos modos de pensar. O argumento ancora-se em alguns aspectos da chamada filosofia ameríndia, tematizando uma possível e desejável interlocução com outras vozes e sistemas de pensamento. Nesse percurso, aposta-se na possibilidade de pensar a

Universidade Federal de Pernambuco (UFPE). Recife, Pernambuco, Brasil. E-mail: <alexkilaya@uol.com.br>; $<$ http://orcid.org/00000003-0982-6581>.

II Doutor em Sociologia pela Universidade Federal de Pernambuco (UFPE). Recife, Pernambuco, Brasil. formação humana sob os traços ainda tênues de uma abertura ao outro enquanto esforço sistemático para promover o diálogo efetivo com diferentes matrizes culturais e epistêmicas.

Palavras chaves: Filosofia da Educação; pesquisa; perspectivismo ameríndio. 


\section{Abstract \\ Contributions of the amerindian perspectivism to the research in Philosophy of Education}

This speculative essay examines the role non-Western systems of thought can undertake in philosophical-educational research. It aims to query about the way in which the field of Philosophy of Education, in Brazil, has acknowledged plurality in the ways of thinking. The concept is underpinned in some aspects of the so-called Amerindian philosophy, thematizing a possible and desired interlocution with other voices and systems of thought. Following this path, there is an investment in the possibility of thinking human development through the still tenuous traces of openness to the other as a systematic effort to promote an effective dialogue with different cultural and epistemic matrices.

Keywords: Philosophy of Education; research, amerindian perspectivism.

\section{Notas introdutórias}

O presente texto interroga como o campo da Filosofia da Educação, no Brasil, tem reconhecido a pluralidade de outros modos de pensar. A intenção é apreender a emergência de abordagens comumente subalternizadas pela Filosofia da Educação, a fim de problematizar a interlocução desse campo com formas de pensamento distintas das privilegiadas pela historiografia filosófica. Sabe-se que a filosofia ocidental tem ignorado ideias oriundas da América Latina, da África e da Ásia, colocando inclusive em questão a legitimidade e a possibilidade mesma da filosofia nesses contextos.

Por essa razão, abordagens decoloniais têm sugerido a promoção de "diálogos interfilosóficos", visando a produzir uma pluralidade de sentidos sobre as bases que sustentam nossas pretensões de conhecimento (Grosfoguel, 2016, p. 45). Esse posicionamento, vale ressaltar, não significa celebrar a visão multiculturalista em torno da diversidade epistêmica do mundo, deixando intocadas as estruturas de poder que conferem valor de verdade aos processos de racionalização e validação dos saberes.

Também não se trata de reivindicar para esses outros sistemas de pensamento o direito de serem o novo solo determinante dos significados da experiência filosófica. Pois isso apenas substituiria a "posse da chave" dos conhecimentos legítimos (Nogueira, 2013, p. 4) e reproduziria a compreensão da filosofia como um terreno para exclusão das vidas e dos destinos dos outros.

Com base nessas assertivas mais gerais, o argumento está organizado em dois movimentos analíticos. Inicialmente, mobilizam-se os diagnósticos presentes nos arquivos do Grupo de Trabalho em Filosofia da Educação da Associação Nacional de Pós-Graduação e Pesquisa em Educação 
o perspectivismo ameríndio é uma abordagem antropológica que tenta aproximar a ontologia de grupos indígenas das terras baixas sul-americanas aos nossos sistemas de pensamento, extraindo implicações filosóficas e políticas (Viveiros de Castro, 1996).

2 Etimologicamente, a noção de essays está relacionada aos termos latinos exagium (pesar) e exigere (testar) e, em francês, a essayer (colocar à prova) e essai (tentativa), carregando a ideia de uma reflexão especulativa, enfatizando-se o caráter contingente de uma interpretação. Enfim, o ensaio funciona como um quadro de orientação acerca de um ponto de vista situado (Boorstin, 1995).

3 Essa é a razão porque o leitor não encontrará aqui a disposição formal que segue a lógica estabelecida pelas metodologias científicas tradicionais. No lugar dos objetivos, geral e específicos, e da fundamentação teórico-metodológica que define os critérios de coleta e análise de dados, a orientação é dada pelas questões que almejam abrir o debate acerca de um saber ainda não institucionalizado. $\mathrm{O}$ argumento é exposto na forma de momentos "que se entretecem como num tapete" (Adorno, 1986 p. 167).
(ANPEd). Mais especificamente, articulam-se as conclusões presentes em dois trabalhos produzidos, no ano de 2013, na 36 a Reunião Nacional da ANPEd, que abordam a produção recente e os rumos da Filosofia da Educação brasileira (Severino, 2013; Dalbosco; Pagni, 2013), para, em seguida, provocar uma interlocução dessas análises com o que vem sendo denominado de filosofia ameríndia ou perspectivismo ameríndio, tematizando suas possíveis contribuições para a pesquisa em Filosofia da Educação em nosso País. ${ }^{1}$

Trata-se de um ensaio de natureza especulativa, o que significa dizer que o gesto de pesquisa aqui implicado se sustenta pela intenção de colocar à prova um percurso experimental de pensamento. ${ }^{2}$ Nos termos de Larrosa (2004), o ensaio modula uma forma específica de análise situada entre a experiência e o pensamento, que produz certa relação com o presente. No entanto, "não se trata do presente como realidade, mas como experiência", ou seja, "trata-se de dar forma a uma experiência do presente" (Larrosa, 2004, p. 34), e é essa experiência do presente que se torna o foco do argumento a ser pensado em uma dada ordem do saber. Assim, não casualmente, o ensaio é o próprio gênero da crítica, isto é, "da crise de uma certa forma de pensar, de falar, de viver" (Larrosa, 2004, p. 38).

A crítica desdobrada no ensaio, pensado como o "corpo vivo da filosofia", é sempre parcial, provisória, aberta, sem fundamentos normativos ou transcendentes. Como se sabe, a compreensão de posicionamento deriva dos trabalhos tardios de Foucault (1998, p. 13), para quem a atividade filosófica configura-se como um trabalho crítico do pensamento sobre o próprio pensamento, colocando em questão a possibilidade mesma de poder se pensar diferentemente. O ensaio filosófico exige, antes de tudo, o "exercício de um saber que lhe é estranho" (Foucault, 1998, p. 13). Nessa direção, um dos sentidos imanentes do ato de pensar e pesquisar por meio do ensaio consiste em acolher outros pontos de vista, que permitam pensar diferentemente nossa compreensão do mundo e da educação. ${ }^{3}$

Logo, a escolha do perspectivismo ameríndio como alvo de interlocução com a Filosofia da Educação brasileira não é arbitrária. Segundo Viveiros de Castro (2012, p, 151), nos últimos anos, temos vivenciado o que alguns cientistas chamam de filosopausa, ou seja, o "fim do período 'produtivo', no sentido empresarial do termo [e] começo de uma etapa de retrospecção marcada por certa elocução sapiencial", que visa a explorar as "transições e as transações" entre a antropologia e certos ramos da filosofia - em particular a metafísica, especulativa ou experimental -, cujo sentido último reside na abertura de um campo de diálogo ancorado em novos objetos de estudo para leituras ainda por vir.

Além disso, cumpre recordar o papel que a reificação ameríndia desempenhou nas querelas intelectuais que estão na base do neotomismo, estruturante dos modos de abordar a educação no Brasil, bem como na concepção de tutela estatal para os povos ameríndios cujas repercussões em nossa cultura política ainda hoje são mais que evidentes. Defende-se, então, a existência de uma filosofia ameríndia enquanto um sistema de pensamento que focaliza os processos de formação do sujeito pela noção 
de ponto de vista, diferindo da ontologia ocidental que usa um dado ponto de vista para criar ou delimitar um objeto que se torna o alvo privilegiado de análises e investigações. O perspectivismo ameríndio, ao contrário, oferece uma percepção renovada sobre os diferentes espelhos, nos quais tanto o educador como o filósofo da educação enxergam as partições ontológicas e epistêmicas que constituem o cerne da sua reflexão. Com isso, essa abordagem pode nos ensinar a enxergar as próprias culturas como intercessoras de um saber passível de ampliar os sentidos que atribuímos à educação, ensejando uma abertura radical à alteridade e à escuta do ponto de vista do outro, tão necessária como urgente nos tempos que correm.

\section{O ethos vigente nas pesquisas em Filosofia da Educação no Brasil}

As tentativas de refletir acerca das pesquisas em Filosofia da Educação, no Brasil, são obrigadas a se confrontar com uma persistente característica do pensamento educacional brasileiro: o agrupamento nas chamadas tendências pedagógicas, cuja característica geral consiste em negar, como parciais e incompletas, classificações anteriores, ao mesmo tempo que se apresenta outra tendência portadora de novas virtudes, multiplicando-se indefinidamente o número das tendências disponíveis.

Essa forma de leitura torna visível um modo dualístico de pensar a educação que se configurou historicamente, de fato e de direito, como uma verdadeira tendência do campo acadêmico brasileiro. As pesquisas do professor Demerval Saviani expressam essa situação ao apreenderem o conhecimento pedagógico nacional como sujeito a oscilações pendulares, resultando em confrontos em torno das metas da própria educação. Tudo se passa como se as ideias pedagógicas brasileiras extraíssem seu caráter específico ou paradigmático de tendências contrapostas: pedagogia conservadora versus pedagogia progressista, pedagogia católica (espiritualista) versus pedagogia leiga (materialista), pedagogia da essência versus pedagogia da existência (Saviani, 2007).

Conduzindo esse cenário, como se quase englobasse todas as demais oposições, está a distinção notável entre a pedagogia tradicional e a pedagogia nova, cujos integrantes em permanente litígio buscam elaborar seus discursos em relação aos oponentes reais ou imaginários. Nesse contexto, parte significativa das pesquisas em Filosofia da Educação também se propõe a contrapor várias abordagens como um procedimento analítico comum (Tomazetti, 2003). Situação que contribuiu para afetar o tratamento teórico e metodológico das questões que articulam as investigações no âmbito da Filosofia da Educação. No entanto, mais do que tentar superar ou transcender esse ethos, faz-se necessário antes problematizar o gesto fundante de pensar os problemas educacionais com base na construção de quadros classificatórios dicotômicos.

Esse modo de tratamento analítico das teorias filosófico-educacionais contribuiu para cristalizar posições instáveis, seja simplificando-as, seja excluindo determinados autores e pensamentos da esfera dos debates. Isso 


\footnotetext{
4 O argumento defendido por Severino (2006), que não se esquivou de produzir suas próprias pesquisas sobre as tendências filosófico-educacionais em nosso País, representa uma posição importante na medida em que parte do pressuposto de que, na cultura ocidental, a educação foi sempre vista como processo de formação humana. Logo, quando se fala em educação, para além de qualquer processo de qualificação técnica, é a ideia reguladora de Bildung que deveria servir de parâmetro na análise dos sentidos da educação.
}

porque os quadros binários acabam por se sobrepor à seleção das temáticas e dos autores, ao mesmo tempo que transpõem resultados de investigações particulares para sistematizações de alcance totalizador. Nesse contexto, o diagnóstico do professor Antonio Joaquim Severino (2013) é bastante preciso ao afirmar que a proliferação de estudos dessa natureza decorre, em grande medida, da fragilidade das pesquisas que abdicam do esforço de compreensão a respeito do próprio sistema de pensamento dos autores abordados, gerando-se análises e interpretações que cindem as dimensões epistêmica, axiológica e antropológica, que comumente materializam uma determinada ideia ou tendência pedagógica. ${ }^{4}$

Em uma direção oposta, Severino propõe outro enfoque para demarcar as pesquisas filosófico-educacionais, indicando o(s) sentido(s) relacionados à formação humana como critério específico de análise não apenas das ideias, mas das próprias pesquisas. As investigações em Filosofia da Educação são pensadas como modos de elucidação dos enigmas da formação humana, o que permite ultrapassar as abordagens que concebem de forma dual o ato educativo. Como resultado concreto, as pesquisas nesse campo deixariam de assumir um papel meramente sintetizador de tendências para se tornarem "uma exigência propriamente filosófica" (Severino, 2006, p. 622).

Nessa direção, na 36a Reunião Nacional da ANPEd, realizada no ano de 2013, em uma pesquisa encomendada pelo Grupo de Trabalho em Filosofia da Educação (GT 17), o próprio Severino propôs um gesto considerado vital para as investigações atuais e futuras da área: o reconhecimento da pluralidade da Filosofia da Educação brasileira. Considerando o "balanço já feito" ao longo de mais de 20 anos pelo GT 17, ele propôs o desafio de se estudar rigorosa e metodicamente como pensamentos específicos têm se situado nesse campo (Severino, 2013, p. 3), defendendo que essa é uma condição necessária para a ultrapassagem de um debate histórico sustentado univocamente em preocupações com a identidade da Filosofia da Educação.

Esse posicionamento reverbera e se entrecruza com as análises que já vinham sendo expostas de que, para além do esforço de autonomização do campo, os trabalhos situados na Filosofia da Educação precisariam buscar um terreno de interlocução (Valle; Kohan, 2004), tendo em vista a pluralidade temática existente faticamente nessa área, cujos reflexos e refrações exigem potencializar o diálogo entre perspectivas. No limite, entende-se que a pluralização das abordagens teóricas tornaria mais premente não apenas a questão dos temas e autores propostos, mas a clareza e a precisão dos procedimentos implicados na pesquisa da área. Esse debate trouxe à tona uma série de perguntas sobre o que significa pensar a formação humana pela ótica da pesquisa educacional, bem como sobre os aspectos formativos implicados no processo de investigação.

O alvo da problematização são as próprias condições que sustentam o ato de filosofar em educação. Mais do que a defesa de uma concepção específica de Filosofia de Educação, destacam-se antes os saberes que diferentes concepções podem gerar na pesquisa educacional. Desdobra-se então uma reflexão mais precisa em torno do processo de academicização 
das pesquisas na área, cada vez mais hiperespecializadas, assentadas em análises históricas ou reduzidas a uma dinâmica de empiricização crescente (Dalbosco; Pagni, 2013). Engana-se, no entanto, quem pensa que se trata apenas de um desafio de natureza epistemológica. Pois, se é verdade que a pluralização crescente das temáticas passou a corresponder a um maior número de investigações que se ocupam de sistemas específicos de pensamento, identificando suas contribuições singulares para o pensamento educacional, permanece a dificuldade de trabalhar e debater o que guarda dissonância com as grades de análise privilegiadas.

Em outros termos, o desafio ainda reside em construir uma disposição para que seja possível acolher as várias perspectivas como tentativas legítimas de busca e experimentação de novos sentidos para o ato educativo, admitindo-se que, mais importante do que classificar autores e abordagens, é delimitar suas contribuições para a experiência de pensar a educação. A aposta residiria na possibilidade de considerar as várias contribuições filosófico-educacionais descoladas da defesa dogmática de um discurso de verdade, buscando-se perspectivar as abordagens, a fim de desvelar como cada uma exprime certo modo de ver e de viver os problemas educativos (Gallo, 2007).

Esse tipo de exigência opera uma ideia de "crítica" distinta da tradição que concebe a pesquisa em Filosofia da Educação como

uma espécie de investigação (suplementar) que tenta compreender, julgar e criticar a coerência, os valores, as observações, as reivindicações de conhecimento, a racionalidade, os objetivos, os princípios, as razões e os argumentos que estão presentes nos discursos e nas práticas educacionais. (Masschelein; Simons, 2014, p. 10).

A tradição ocidental tem concebido o trabalho filosófico fundamentalmente como de julgamento e esclarecimento das suas pretensões de validade normativa ou epistemológica. Por esse motivo, os discursos e escritos derivados dessa forma de conceber e praticar a pesquisa em Filosofia da Educação reivindicam para pesquisadores e estudiosos "um papel crítico-julgador" da realidade educacional, colocada "sob minucioso exame" (Masschelin; Simons, 2014, p. 11).

Tropeça-se aqui no que talvez seja o maior obstáculo epistêmico da pesquisa em Filosofia da Educação na atualidade: como fazer do gesto mesmo da investigação um exercício formativo capaz de refinar o trabalho conceitual da área?

A resposta a esse questionamento decisivo, tanto na ótica de Severino (2013) quanto nos estudos de Dalbosco e Pagni (2013), indica que o trabalho filosófico-educacional não pode ser tão especializado a ponto de formar círculos herméticos com análises que se dedicam meramente a comentar textos. Mas também não pode ser tão abrangente a ponto de diluir as especificidades do campo ao dissociar as pesquisas em curso dos problemas que atravessam a práxis cultural e educacional.

Patrice Maniglier (2013), em um contexto mais abrangente, afirma, contudo, que o problema é delicado e exige uma espécie de "comparatismo 
superior em filosofia", posto que o desejo de filosofia supõe, em alguma medida, abdicar da percepção de que esse desejo se configura apenas na "passagem para o limite do ideal racional", quer dizer, que a filosofia consistiria tão somente "em fornecer uma justificativa válida a tudo o que é, para não deixar nada sem razão" (Maniglier, 2013, p. 229). Uma das tarefas da atividade filosófica seria compreender como os próprios equívocos presentes no campo permitem que se construa algo como uma "lógica da multiplicidade". A noção de equívoco, nesse caso, responde a uma dimensão do filosofar que se poderia chamar de exigência de singularidade, sem a qual essa atividade perderia os direitos a "certa imaginação", uma vez que não se trata na filosofia de descobrir ou verificar, mas de propor e apresentar mundos (Maniglier, 2013, p. 247).

Nesse contexto, a pesquisa filosófica em educação passa a ser vista como um esforço deliberado para se introduzir o máximo de descontinuidade no pensamento. A intencionalidade explícita é fazer sentir o que é uma alteridade impondo-se ao pensamento uma fenda que o submete a uma escolha sem medida, posto que não se pode legislar sobre o pensável. As pesquisas em Filosofia da Educação configuram-se, assim, como um trabalho contínuo de exposição às contingências das diferentes formas de vida, desdobrando uma prática ativa de desobediência epistêmica que emerge inseparável do exercício de abertura ontológica à alteridade, como condição para pensar a concretude dos problemas educacionais. Isso significa que as pesquisas em Filosofia da Educação precisam colocar também o próprio pesquisador à prova, levando-o a problematizar os regimes de verdade aos quais o sujeito humano, na história do pensamento ocidental, destinou-se como detentor exclusivo do papel de produtor de conhecimentos. Esse gesto aparentemente extemporâneo permite redimensionar os problemas da pesquisa em Filosofia da Educação fora das coordenadas epistêmicas que sustentam a identidade e os condicionantes lógicos que fazem vingar um sentido unívoco de razão, disparando um tipo de crítica constituída em carne e osso às formas habituais de se viver no mundo.

\section{O equívoco perspectivista como prova da verdade: do ponto de vista da diferença à diferença como ponto de vista}

Michel Foucault (2004), nas suas pesquisas acerca da ética do cuidado de si na Antiguidade greco-romana, articulou uma forma renovada de crítica filosófica considerando o vocabulário da espiritualidade e dos exercícios espirituais. A espiritualidade seria o "preço que se paga" para viver uma determinada experiência com a verdade.

O efeito desse deslocamento analítico sobre as pesquisas em Filosofia da Educação é duplo. Por um lado, contribui para a dissolução do logocentrismo. Por outro, move investigações que desconstroem o substancialismo prefigurado na axiomática do sujeito moderno. A espiritualidade, pensada como o "real da filosofia", exige que a Filosofia da Educação questione o sujeito moderno que, condenado ao círculo do 
conhecimento, não pode indagar o lastro de sua própria formação. Mais: a espiritualidade torna-se um convite para que o outro nos interpele, esse outro que nos escapa como um estranho, um diferente, colocando em jogo a ideia de que em toda escolha teórico-metodológica opera não apenas o "teor de verdade contido em uma doutrina filosófica", mas, antes, toda escolha expõe o pesquisador a certa "experiência educativa" (Pagni, 2011, p. 15), que cobra pensar a pesquisa filosófico-educacional como algo mais do que produção de conhecimentos. ${ }^{5}$

A pesquisa formativa é um tipo de pesquisa pedagógica e dá um certo conteúdo [preciso] ao termo 'pedagógico'. [...] Por um lado, 'pedagógico' é genitivo do objeto e remete a um campo de pesquisa: a uma pesquisa acerca do campo educativo (a escola, a criança, a aprendizagem, o currículo, etc.). Por outro lado, como genitivo do sujeito, o termo 'pedagógico' remete à natureza da pesquisa em si: à dimensão educativa ou formativa da própria atividade de pesquisa. (Masschelein; Simons, 2014, p. 56).

A singularidade da pesquisa, orientada espiritualmente, reside no que significa um "acesso à verdade", pressupondo dois tipos diferentes de "mestria pedagógica" e desdobrando dois pontos de vista. Enquanto o primeiro busca restabelecer a relação entre Filosofia e Educação, "concebendo a primeira como uma prática que tem um sentido eminentemente formativo e que deve nortear a ação educativa, particularmente, o trabalho do pensar suposto pela ética de si", o segundo parece tencionar "que a segunda seja o objetivo do caráter normativo recuperado pela primeira, com o objetivo de oferecer um fundamento epistemológico e pós-metafísico" (Dalbosco; Pagni, 2013, p. 15).

A diferença entre esses dois pontos de vista subjacentes às tradições filosóficas que os compreendem afeta diretamente o desenvolvimento atual da Filosofia da Educação brasileira e, por extensão, das pesquisas desdobradas nesse âmbito. A diferença reside na exigência mesma de fazer do "exercício paciente de escutar" (Dalbosco; Pagni, 2013, p. 16) outros pontos de vista uma condição para avançar, seja refratando, seja inovando a Filosofia da Educação.

Em síntese, admite-se que a maturidade teórica e metodológica das pesquisas no campo passa a se concretizar menos na defesa de uma identidade articulada pela ideia expressa no sintagma "fundamentos da educação" e mais em um terreno efetivo de abertura e interlocução atravessado pela crítica e pelo acolhimento da pluralidade.

Um modo de "pôr à prova" a potência desse argumento passa pela interrogação sobre como esse campo tem dialogado com as chamadas filosofias da diferença. Sem poder dimensionar todas as polêmicas envolvidas no debate em torno de uma possível e desejável "teoria filosóficoeducacional da diferença", ressalta-se que a diferença, uma vez convertida em decisão filosófica, mas também em uma espécie de palavra de ordem, abriu uma espécie de abismo na Filosofia da Educação, instalando uma disputa sem fim.
5 Para a tradição crítica, o conhecimento é o que nos permite obter a verdade, exigindo que se cumpram determinadas condições (epistêmicas) para a aquisição de saberes considerados verdadeiros. Para a tradição espiritual, a transformação do próprio pesquisador é considerada a condição seminal para se obter um certo tipo de verdade (Masschelein; Simons, 2014). 
Acompanhando a guinada ontológica (Meillassoux, 2015) voltada a se comunicar com as "margens do Ocidente", o perspectivismo ameríndio subverte a herança iluminista (Latour, 1994; Stengers, 2002), provocando mudanças significativas nas distinções entre natureza e cultura, universal e particular, corpo e alma etc. (Viveiros de Castro 1996, 2010, 2012).
Os efeitos sintomáticos dessa situação têm retroagido sobre o campo educacional como um todo, afetando inclusive os modos de convivência com a pluralidade diagnosticada como um avanço. Pois, como viver o exercício paciente da escuta de outros pontos de vista quando a própria sintaxe da diferença, com sua ênfase na textualidade, no desejo ou no poder, é acusada de promover o relativismo, o individualismo e até o neoliberalismo na educação? As filosofias da diferença, como se sabe, têm sido identificadas com a impotência pós-moderna em pensar alternativas ao mundo vigente. O seu caráter resignado é expressão de uma aceitação da derrota das metanarrativas educacionais, o que redundaria em uma cumplicidade com a ordem capitalista vigente.

Embora não se refira diretamente aos filósofos da diferença, mas aos pós-modernistas, a leitura delineada por Harvey (1992) tem servido de esquema tradutor paradigmático do pensamento da diferença na educação. Para esse autor, a chamada condição ou posição pós-moderna simples é de que, "como a representação e a ação coerentes são repressivas ou ilusórias (e, portanto, fadadas a ser autodissolventes e autoderrotantes), sequer deveríamos tentar nos engajar em algum projeto global. O pragmatismo se tornando então a única filosofia da ação possível" (Harvey, 1992, p. 55).

A conclusão que se extrai daqui é que os filósofos da diferença ficariam limitados às seguintes alternativas: (i) resignação com a vitória histórica do capitalismo; (ii) contestação da ordem vigente, mas a partir de uma ótica fragmentada.

Mesmo que se reconheçam nessas alternativas algumas posições presentes em determinadas reflexões filosófico-educacionais que adotam o ponto de vista da diferença, é preciso ter cautela e problematizar alguns "equívocos" existentes nessa leitura reducionista do ponto de vista das filosofias da diferença. Um desses equívocos é a noção mesma de ponto de vista. O problema imediato para o argumento é que, em nossa cultura, falar sobre perspectiva, quase sempre, reduz-se a "uma simples questão de fazer previsões ou avaliar probabilidades". (Almeida, 2014, p. 411). Em outra direção, os povos ameríndios, por exemplo, expressam uma compreensão distinta, adotando uma noção de perspectiva que perturba nossas heranças ontológicas e epistêmicas.

A noção de perspectiva, presente na filosofia ameríndia, postula e exige uma refinada prática de tradução entre mundos. Desse modo, o equívoco funda-se no princípio da coexistência mais do que no de conjunção, mantendo a heterogeneidade e não a unidade, uma espécie de síntese disjuntiva. E na direção do equívoco, portanto, que parece possível, a partir desse outro pensamento, pensar outro estado futuro das pesquisas em Filosofia da Educação. ${ }^{6}$ Nesse âmbito, as preocupações epistemológicas cedem espaço a um interesse crescente pelas múltiplas ontologias que constroem o vir-a-ser dos entes. A filosofia ameríndia distingue-se da ontologia clássica ocidental no que concerne ao empenho em desvelar a natureza última do ser ou dos diferentes modos de ser do mundo.

Para o perspectivismo ameríndio, todo ponto de vista configura e expressa uma relação em que entra em jogo a criação ou recriação de modos 
de existência, os quais não se reduzem à interpretação ou à representação. À diferença das abordagens culturalistas que partem do princípio de que as pessoas são capazes de representar o mundo de diferentes maneiras, isto é, admitem uma realidade e diversas culturas, o perspectivismo ameríndio concebe a possibilidade da existência de outras realidades, agenciadas por uma alteridade interlocutora, o que leva a uma apreensão mais radical do conceito de diferença.

O relativismo cultural, um multiculturalismo, supõe uma diversidade de representações subjetivas e parciais, incidentes sobre uma natureza externa, una e total; os ameríndios propõem o oposto: uma unidade representativa ou fenomenológica puramente pronominal, aplicada indiferentemente sobre uma radical diversidade objetiva. Uma só cultura, múltiplas naturezas, epistemologia constante, ontologia variável - o perspectivismo é um multinaturalismo, pois uma perspectiva não é uma representação. (Viveiros de Castro, 2002, p. 379).

Observe-se que não se trata de colocar a natureza no plural. O perspectivismo ameríndio inclui não só a ideia de que existe uma singularidade dos pontos de vista própria de cada espécie, mas de que toda definição ontológica é posicional e provisória. A noção de múltiplos pontos de vista não implica que toda perspectiva é igualmente válida, menos ainda que uma representação correta e verdadeira do mundo não existe. O que essa análise pretende elucidar é a não existência de um ponto de vista absoluto, independente dos entes, ou uma natureza externa e unificada que seria diferentemente representada pelos vários sujeitos. Nesse aspecto, o perspectivismo não é nem universalista nem relativista, mas relacionalista. Nos termos de Viveiros de Castro (2002, p. 385), "não existem pontos de vista sobre as coisas, mas que as coisas são pontos de vista. E pontos de vista não são ilusões ou opiniões, mas diferenças reais e objetivas".

[As] diferenças são relacionais (você não vê uma diferença - uma diferença é o que o faz ver). O ponto, em resumo, é que as perspectivas não consistem em representações (visuais ou qualquer outra) de objetos por sujeitos, mas em relações de sujeitos e sujeitos. (Viveiros de Castro, 1996, p. 29).

Essa compreensão da diferença, a partir da filosofia ameríndia, pode conter algumas implicações importantes para a pesquisa em Filosofia da Educação, sobretudo para a reconhecida ou almejada interlocução entre diferentes pontos de vista. A ênfase na relação com a alteridade indica que a diferença não se opõe à identidade. A formação de uma dada identidade ocorre no estabelecimento de relações que situam o sujeito para além de si mesmo. A alteridade remete, portanto, a uma relação sempre presente que altera tanto o eu quanto o outro, uma alteração, relações entre relações (Andrello, 2006).

O modo de interlocução com a alteridade não é o da reciprocidade ou da unificação comunicativa entre os sujeitos, mas uma forma agonística em que prevalece a figura da variação infinita. A identidade torna-se um caso particular da diferença. Assim, para o perspectivismo ameríndio, só há relação com a alteridade se houver diferenciação. Toda relação é 
em si mesma diferença e a diferença vem à tona por meio da relação. A interlocução com outros pontos de vista pode atualizar tanto o conflito como a contraefetuação, isto é, um movimento de produção de semelhanças, a fim de construir alianças que visam a acolher os processos engendrados pelo contato com a alteridade, diferindo da postura hegemônica, na tradição filosófica do Ocidente, que pensa a relação com o outro enquanto tentativa de unificação, a fim de que sejam superadas as diferenças.

No perspectivismo ameríndio, ao contrário, pressupõem-se mundos múltiplos intensamente conectados por meio de suas próprias diferenças. A percepção é que qualquer identidade se configura como um estado revogável e provisório. Os pontos de vista expressam a metamorfose como possibilidade virtual imanente às nossas relações, uma vez que o lugar do outro já está inscrito no próprio exercício do pensamento. O respeito às diferenças remete a uma dinâmica radical: a necessidade de devoração recíproca e o risco de deixar de ser quem somos. Tornar-se um outro não como processo dessubjetivante, mas sim alterante. Isso porque o ponto de vista do outro não é considerado um espelho, mas um destino (Viveiros de Castro, 1992).

Essa ideia permite elucidar e abrir outras vias para o modo como se pesquisa em Filosofia da Educação, permitindo examinar as consequências implicadas no desejo de realizar uma interlocução com outros pontos de vista. As relações vistas como um processo de desequilíbrio contínuo contribuiriam para transformar diferenças extrínsecas em diferenças intensivas, quer dizer, diferenças imanentes a uma dinâmica de singularização que incorpora sem precisar anular as distâncias existentes entre os pontos de vista. Nessa ótica, os conflitos podem inclusive desaparecer, mas não porque sejam recalcados, e sim porque se tornam uma das condições de existência dos próprios sujeitos que praticam uma atividade que depende necessariamente da relação com outrem.

As pesquisas em Filosofia da Educação, portanto, emergem como exercício ético-político de predação subjetivante. Uma prática simultaneamente formativa e descolonizante da experiência de pensar que atesta e prova a coragem da verdade implicada no desejo de filosofar (Foucault, 2012). Como resultado, os pesquisadores são convidados a se descolarem da pretensão de produtores ou detentores de uma posição dogmática ou absoluta. Mais uma vez: não se trata de relativizar a verdade, mas de reconhecer a verdade da relação. O desafio não passa pela tentativa de conciliar as diferentes perspectivas ou de julgá-las como verdadeiras ou falsas, pois isso seria recair na compreensão do ponto de vista como representação. A questão seria antes como lidar com os desencontros entre as diferentes formas de conceber e praticar a Filosofia da Educação, formas mediadas pelo contato com outros pontos de vista. As diferenças teóricas ou políticas, nesse caso, são vistas como o oxigênio das pesquisas, permitindo explorar suas afinidades potenciais e suas alianças precárias. ${ }^{7}$

Pesquisar em Filosofia da Educação exigiria menos passar da identidade à diferença (Marinho, 2014) do que incorporar outros pontos de vista. A intenção torna-se então angariar o máximo de diferença no esforço de 
interlocução para que os próprios sentidos do ato de educar se enriqueçam, constituindo uma forma de "guerra por outros meios" se se considera a guerra justamente como uma relação radical com a alteridade. Isso quer dizer: pesquisar como que saindo de si para ir ao encontro de si, mas transformado pelos sentidos agenciados na voz do outro.

O verdadeiro perigo que a filosofia combate não é mais a opinião, nem a superstição, nem mesmo a besteira, no sentido no qual Deleuze a define. Mas, é o mal entendido, sob [...] duas formas, o vago por sua forma pacífica, e a intransigência (ou o dogmatismo) por sua forma agressiva. Nos dois casos, trata-se de uma incapacidade para operar a diplomacia, seja porque se vincula de maneira demasiado precisa a uma prática (o que Badiou chama sutura), seja, ao contrário, não se tem mais nenhuma estima acerca de nenhuma prática particular, a palavra, aqui, sendo realmente separada de toda outra prática, reduzindo-se ao que é preciso chamar de tagarelice. (Maniglier, 2013, p. 266).

Não se trata de uma tarefa simples. É uma questão de se ter o ouvido certo para escutar (e não desfazer) os equívocos que nos conduzem na ação mesma de pesquisar. Os equívocos deixam de ser tomados apenas como uma forma de dissenso ou um ruído que atrapalha a conversação, mas como algo que realça e potencializa a interlocução.

Logo, trata-se de habitar o equívoco, posto que ele não é algo que impede a relação, mas aquilo que a funda e a impulsiona. O equívoco é a própria materialização de uma "diferença de perspectiva" (Viveiros de Castro, 2007, p. 102). Assim, se pesquisar e filosofar é sempre forçosamente reestabelecer a heterogeneidade, enquanto o "senso comum tende a totalizar, a harmonizar, ou pior: supor tal harmonia" (Maniglier, 2013, p. 266), então, que outros pontos de vista, que o ponto de vista do outro não precise se converter em um mesmo para que possa circular, mas que circulando entre nós consiga alterar e desestabilizar esse mesmo que somos.

\section{Para (não) concluir}

Como em todo ensaio especulativo, as conclusões permanecem inarticuladas, quer dizer, abertas. Finaliza-se, então, com um pedido de interlocução, pois sem isso todo ensaio perde parte de sua função formativa, visto que o que se busca é abrir outros pontos de vista para pensar os desafios da pesquisa em Filosofia da Educação.

Trata-se de uma tarefa urgente a julgar pela ambiência políticoinstitucional que nos cerceia, segundo a qual cada pesquisador passa mais tempo gerindo a "paperização" da sua produção do que propriamente fazendo e pesquisando em Filosofia da Educação. A regra metódica vigente é simples e eficiente, consistindo no represamento das nossas tendências especulativas.

Talvez, por isso, seja mesmo difícil avançar em direção ao terreno de interlocução almejado pelos pesquisadores do campo. Mas, por outro lado, se não houver qualquer tentativa de modificar a pedagogia subjacente aos processos de formação dos pesquisadores em Filosofia da Educação, será 
praticamente impossível incorporar a pluralidade como base do terreno de interlocução que a área solicita e reclama, para acolher a alteridade de outros pontos de vista como elemento intrínseco da pesquisa filosóficoeducacional. Para tanto, é preciso abrir um debate franco acerca da própria cisão instalada entre os pesquisadores, baseada nos marcadores de sentido que acabam funcionando como "vasos não comunicantes", em que todos se ignoram solene e diplomaticamente, ou pior, no círculo hermenêutico da "teoria da vara", que, em suas curvaturas ou quebraduras, alimenta uma "comunidade de desconversação" (Marinho, 2014).

Assim, uma aliança, mesmo que precária, com a filosofia ameríndia e sua ênfase no ponto de vista do outro como condição para a formação e a transformação de determinados pontos de vista permite sustentar o desejo de uma Filosofia da Educação comprometida com os desafios da educação brasileira, ocupando o espaço público e expandindo suas intervenções para além das fronteiras disciplinares. Essa ocupação tornou-se um gesto essencial, pois, se em um passado não tão distante a Filosofia da Educação pactuou, ainda que silenciosamente, com a reificação do pensamento ameríndio, excluindo-o de suas pragmáticas políticas e escolares, hoje, quem sabe, seja esse mesmo pensamento uma condição vital para que seja possível reverter os equívocos geradores de tanta brutalidade e violência dirigidas a tudo que nos soa diferente.

O perspectivismo ameríndio pode, então, contribuir para subverter as técnicas e os dispositivos, tanto políticos quanto epistêmicos, de captura que almejam o silenciamento e a invisibilização de outras filosofias e outros sujeitos da educação, colocando no cerne de nossas pesquisas uma questão aparentemente aberrante: onde é que as nossas próprias instituições e disciplinas precisam se dissolver para que a formação prossiga?

Essa é uma questão central para que as pesquisas em Filosofia da Educação sobrevivam com a virulência que a especifica. Em todo caso, a instituição que interessa aqui dissolver é também um tipo de amor e de amizade, posto que a Filosofia da Educação é sempre uma questão de pulsão, de afetos e de vísceras.

Nunca houve filosofia isenta de perigos, a Filosofia da Educação mais que qualquer outro lugar. Porque mais do que com um depósito de saberes a serem transferidos nos processos pedagógicos, ela lida, antes de tudo, com as possibilidades abertas pela formação dos viventes, revelando nossa própria condição na ausência de certezas apodíticas. A Filosofia da Educação é o que nos permite abrir uma perspectiva sobre a verdade, verdade que se deixa revelar apenas em uma relação, ela mesma, educativa. Uma verdade provisória, precária, mas que tem se mostrado capaz de sustentar alianças imprevisíveis.

Por tudo isso, as pesquisas desenvolvidas nesse campo serão sempre marginais, ou não serão. Marginal se refere à postura de quem, tomando a palavra a partir de suas próprias margens, produz estranhamento e desconforto, deslocando as coordenadas para a autocrítica da própria Filosofia da Educação, ao questionar a multiplicidade dos efeitos formativos que essa instituição pode comportar e acolher na relação viva com outrem. 


\section{Referências bibliográficas}

ADORNO, T. W. O ensaio como forma. In: COHN, G. Theodor W. Adorno. São Paulo: Ática, 1986. p. 167-187.

ALMEIDA, G. A. Perspectivas da filosofia no Brasil do ponto de vista de um scholar. Kriterion: Revista de Filosofia, Belo Horizonte, v. 55, n. 129, p. 411-415, jan./jun., 2014.

ANDRELLO, G. Gilbert Simondon na Amazônia. Nada, n. 7, p. 96-113, 2006.

BARBOZA FILHO, R. Tradição e artifício: iberismo e barroco na formação americana. Belo Horizonte: Ed. da UFMG; Rio de Janeiro: IUPERJ, 2000.

BARCENA, F. La respiración de las palavras: ensayo sobre la experiencia de una lectura imposible. Educación y Pedagogía, Medellín, v. 14, n. 32, p. 23-38, jan./abr. 2002.

BOORSTIN, D. J. Os criadores. Rio de Janeiro: Civilização Brasileira, 1995.

CEPPAS, F. O ensino de filosofia como 'questão clássica' na tradição do pensamento filosófico. Revista Educação, Santa Maria, v. 40, n. 1, p. 5361, jan./abr. 2015.

DALBOSCO, C. A. Por uma filosofia da educação transformadora. In: REUNIÃO ANUAL DA ASSOCIAÇÃO NACIONAL DE PÓS-GRADUAÇÃO E PESQUISA E EM EDUCAÇÃO - ANPEd, 32., 2009, Caxambu. Anais... Rio de Janeiro: ANPEd, 2009.

DALBOSCO, C. A.; PAGNI, P. A. As produções do GT-17 da ANPEd e o seu papel para o desenvolvimento da Filosofia da Educação no Brasil. 2013. Disponível em: <http://www.anped.org.br/sites/default/files/ resources/Hist_rico_GT_Filosofia_da_Educa_o_Pedro_e_Claudio.pdf $>$. Acesso em: 4 set. 2016.

DOMINGUES, I. Painel: filosofia no Brasil - perspectivas no ensino, na pesquisa e na vida pública. Kriterion: Revista de Filosofia, Belo Horizonte, v. 55, n. 129, p. 389-395, jan./jun. 2014.

FOUCAULT, M. História da sexualidade II: o uso dos prazeres. Rio de Janeiro: Graal, 1998.

FOUCAULT. M. A hermenêutica do sujeito. São Paulo: Martins Fontes, 2004. 
FOUCAULT. M. A coragem da verdade. São Paulo: Martins Fontes, 2012.

GALLO, S. Filosofia da educação no Brasil do século XX: da crítica ao conceito. Eccos: Revista Científica, São Paulo, v. 9, n. 2, p. 261-284, jul./ dez. 2007.

GROSFOGUEL, R. A estrutura do conhecimento nas universidades ocidentalizadas: racismo/sexismo epistêmico e os quatro genocídios/ epistemicídios do longo século XVI. Sociedade e Estado, Brasília, v. 31, n. 1, p. 25-49, jan./abr. 2016.

HARVEY, D. A condição pós-moderna. 9. ed. São Paulo: Loyola, 1992.

LARROSA, J. A operação ensaio: sobre o ensaiar e o ensaiar-se no pensamento, na escrita e na vida. Educação \& Realidade, Porto Alegre, v. 29, n. 1, p. 27-44, 2004.

LATOUR, B. Jamais fomos modernos: ensaio de uma antropologia simétrica. São Paulo: Ed. 34, 1994.

LATOUR, B. An inquiry into modes of existence: an anthropology of the moderns. Cambridge, MA: Harvard University Press, 2013.

MANIGLIER, P. Manifesto para um comparatismo superior em filosofia. Veritas, Porto Alegre, v. 58, n. 2, p. 226-271, maio/ago. 2013.

MARINHO, C. M. Filosofia e educação no Brasil: da identidade à diferença. São Paulo: Loyola, 2014.

MASSCHELEIN, J.; SIMONS, M. A pedagogia, a democracia, a escola. Belo Horizonte: Autêntica, 2014.

MEILlASSOUX, Q. Despues de la finitude: ensayo sobre la necessidad de la contigencia. Buenos Aires: Caja Negra, 2015.

NOGUEIRA, R. O conceito de drible e o drible do conceito: analogias entre a história do negro no futebol brasileiro e do epistemicídio na filosofia. Revista Z Cultural, v. 8, n. 2, 2013. Disponível em: <http:// www.revistazcultural.pacc.ufrj.br/o-conceito-de-drible-e-o-drible-doconceito-analogias-entre-a-historia-do-negro-no-futebol-brasileiro-e-doepistemicidio-na-filosofia/>. Acesso em: 20 out. 2014.

PAGNI, P. A. Matizes filosófico-educacionais da formação humana. In: REUNIÃO ANUAL DA ASSOCIAÇÃO NACIONAL DE PÓS-GRADUAÇÃO E PESQUISA E EM EDUCAÇÃO - ANPEd, 34., 2011, Natal. Anais... Rio de Janeiro: ANPEd, 2011. Disponível em: <http://www.34reuniao.anped. org.br/images/trabalhos/GT17/GT17-184\%20int.pdf>. Acesso em: 4 dez. 2012. 
SAVIANI, D. Pedagogia histórico-crítica primeiras aproximações. Campinas: Autores Associados, 2005.

SAVIANI, D. As concepções pedagógicas na história da educação brasileira. 2007. Disponível em: <http://www.histedbr.fe.unicamp.br/ navegando/artigos_frames/artigo_036.html>. Acesso em: 15 abr. 2013.

SEVERINO, A. J. A busca do sentido da formação humana: tarefa da filosofia da educação. Educação e Pesquisa, São Paulo, v. 32, n. 3, p. 619634, set./dez. 2006.

SEVERINO, A. J. Os 20 anos do GT Filosofia da Educação e sua contribuição para a constituição do campo investigativo da filosofia da educação. In: REUNIÃO ANUAL DA ASSOCIAÇÃO NACIONAL DE PÓS-GRADUAÇÃO E PESQUISA E EM EDUCAÇÃO - ANPEd, 36., 2013, Goiânia. Anais... Rio de Janeiro: ANPEd, 2013. Disponível em: <http://www.anped.org.br/sites/default/files/resources/TRAB_ ENCOMENDADO_20_anos_GT_Filosofia_da_Educa_o.pdf $>$. Acesso em: 4 set. 2016.

STENGERS, I. A invenção das ciências modernas. São Paulo: Ed. 34, 2002.

STENGERS, I.; PIGNARRE, P. Capitalist sorcery: breaking the spell. Nova York: Palgrave McMillan, 2011.

TOMAZETTI, E. M. Filosofia da educação: um estudo sobre a história da disciplina no Brasil. Ijuí: Ed. UNIJUÍ, 2003.

VALLE, L.A.B.; KOHAN, W.O. Notas para pensar a filosofia da educação no Brasil. Educação em Revista, Marília, v. 1, n. 5, p. 15-22, jan./jul. 2004.

VIVEIROS DE CASTRO, E. Sociedades indígenas e natureza na Amazônia. Tempo e presença, n. 261, p. 25-26, 1992.

VIVEIROS DE CASTRO, E. Os pronomes cosmológicos e o perspectivismo ameríndio. Mana, Rio de Janeiro, v. 2, n. 2, p. 115-144, 1996.

VIVEIROS DE CASTRO, E. A inconstância da alma selvagem (e outros estudos de antropologia). São Paulo: Cosac\&Naify, 2002.

VIVEIROS DE CASTRO, E. Filiação intensiva e aliança demoníaca. Novos Estudos Cebrap, São Paulo, n. 77, p. 91-126, mar. 2007. Disponível em: $<$ http://www.scielo.br/pdf/nec/n77/a06n77.pdf>. Acesso em: 26 jul. 2013. 
VIVEIROS DE CASTRO, E. Metafisicas canibales. Buenos Aires: Katz, 2010.

VIVEIROS DE CASTRO, E. O medo dos outros. Revista de Antropologia, São Paulo, v. 54, n. 2, p. 885-917, 2011. Disponível em: <http://www. revistas.usp.br/ra/article/view/39650/43146>. Acesso em: 14 dez. 2013.

VIVEIROS DE CASTRO, E. "Transformação" na antropologia, transformação na "antropologia". Mana, Rio de Janeiro, v. 18, n. 1, 2012.

Recebido em 27 de janeiro de 2018.

Solicitação de correções em 16 de abril de 2018.

Aprovado em 7 de maio de 2018. 